Published in final edited form as:

Transl Stroke Res. 2018 June ; 9(3): 201-213. doi:10.1007/s12975-017-0571-1.

\title{
Inactivation of NSF ATPase Leads to Cathepsin B Release After Transient Cerebral Ischemia
}

\author{
Dong Yuan ${ }^{1,2}$, Chunli Liu ${ }^{1}$, and Bingren $\mathrm{Hu}^{1,3}$ \\ ${ }^{1}$ Department of Neurology and Anesthesiology, Shock Trauma and Anesthesiology Research \\ Center, University of Maryland School of Medicine, Baltimore, MD 21201, USA \\ 2Department of Neurology, The First Teaching Hospital, Jilin University, Changchun, China \\ ${ }^{3}$ Veterans Affairs Maryland Health Center System, 10 North Greene Street, Baltimore, MD 21201, \\ USA
}

\section{Abstract}

\begin{abstract}
Neurons have extraordinary large cell membrane surface area, thus requiring extremely high levels of intracellular membrane-trafficking activities. Consequently, defects in the membrane-trafficking activities preferentially affect neurons. A critical molecule for controlling the membranetrafficking activities is the $N$-ethylmaleimide-sensitive factor (NSF) ATPase. This study is to investigate the cascade of events of NSF ATPase inactivation, resulting in a massive buildup of late endosomes (LEs) and fatal release of cathepsin B (CTSB) after transient cerebral ischemia using the 2-vessel occlusion with hypotension (2VO+Hypotension) global brain ischemia model. Rats were subjected to $20 \mathrm{~min}$ of transient cerebral ischemia followed by $0.5,4,24$, and $72 \mathrm{~h}$ of reperfusion. Neuronal histopathology and ultrastructure were examined by the light and electron microscopy, respectively. Western blotting and confocal microscopy were utilized for analyzing the levels, redistribution, and co-localization of Golgi apparatus and endosome or lysosome markers. Transient cerebral ischemia leads to delayed neuronal death that occurs at $48-72 \mathrm{~h}$ of reperfusion mainly in hippocampal CA1 and neocortical (Cx) layers 3 and 5 pyramidal neurons. During the delayed period, NSFATPase is irreversibly trapped into inactive protein aggregates selectively in post-ischemic neurons destined to die. NSF inactivation leads to a massive buildup of Golgi fragments, transport vesicles (TVs) and late endosomes (LEs), and release of the $33 \mathrm{kDa}$ LE type of CTSB, which is followed by delayed neuronal death after transient cerebral ischemia. The results support a novel hypothesis that transient cerebral ischemia leads to NSF inactivation, resulting in a cascade of events of fatal release of CTSB and delayed neuronal death after transient cerebral ischemia.
\end{abstract}

Correspondence to: Bingren $\mathrm{Hu}$.

Conflict of Interest Dong Yuan, Chunli Liu, and Bingren Hu declare no conflict of interest.

Compliance with Ethical Standards: Ethical Approval This article does not contain any studies with human subjects. All the experimental procedures involving using animals were approved by the Animal Use and Care Committee in the University of Maryland School of Medicine. 


\section{Keywords}

$N$-ethylmaleimide sensitive factor ATPase (NSF); SNAREs; Brain ischemia-reperfusion injury; Membrane trafficking; Cathepsin B (CTSB); Golgi fragments; Transport vesicle; Late endosome; Lysosome

\section{Introduction}

Transient cerebral or global brain ischemia leads to delayed neuronal death that occurs after 2-3 days of reperfusion after the initial ischemic episode [1-4]. During the delayed period, all neurons appear perfectly normal under the light microscope [1-4]. Under electron microscopy (EM), however, a massive buildup of protein aggregates is observed in postischemic neurons destined to undergo delayed neuronal death [5-8]. Delayed neuronal death occurs also in the penumbra areas after focal ischemia in animal models and in human brain ischemia patients $[2,3]$.

Neurons have numerous axonal terminals and dendritic branches with extraordinarily large cell membrane surface area, and thus require extremely high levels of intracellular membrane-trafficking activities. This may be why defects in the membrane-trafficking activities preferentially affect neurons and are a hallmark of most, and maybe all, neurodegenerative disorders [9]. Membrane trafficking from one organelle structure to another, or to cell surface membrane, requires membrane-to-membrane fusion via the following core elements: (i) NSF (N-ethyl-maleimide sensitive factor ATPase), (ii) SNAP (soluble NSF attachment protein), and (iii) SNAREs (soluble NSF attachment protein receptors) [10]. NSF is the sole ATPase for regenerating active SNAREs after fusion. SNAP is an adaptor connecting NSF to SNAREs. SNAREs are membrane fusion proteins. Interaction between SNAREs on the two opposite membranes brings them together before fusion. After fusion, SNAREs form inactive complexes and must be regenerated by NSF ATPase for the next round of fusion. During this process, cytosolic free NSF ATPase interacts with SNAREs via an adaptor protein SNAP to dissociate the inactive SNARE complex into individual active SNAREs [11]. There is only a single form of NSF ATPase in most organisms except in Drosophila that expresses dNSF-1 and dNSF-2 [12]. For that reason, NSF deficiency will bring all mammalian neuronal membrane-trafficking activities to a halt [10-14].

Golgi apparatus (Golgi hereafter) is one of the most active membrane-trafficking structures, consisting of trans-Golgi network (TGN) and cis-Golgi network (CGN) in eukaryotes [10]. TGN is the distal structure of Golgi for packing the cargo transport vesicles (TVs) destined to subcellular structures, such as to early and late endosomes or to the cell surface membrane. Late endo-some (LE) represents the stomach of a cell and contains the highest levels of membrane trafficking-related proteins such as NSF, SNAPs, and SNAREs [15-17]. This is because that LE acts as a central hub receiving the following: (i) newly synthesized proteins (e.g., cathepsins) from Golgi, (ii) endocytic cargo from early endosome, and (iii) autophagic cargo from autophagosome. $\mathrm{LE}$ (luminal $\mathrm{pH}=5.5$ ) then fuses with lysosome via an NSF-dependent mechanism to become a more acidic $(\mathrm{pH}<5)$ hybrid endolysosome (EL), also known as the secondary lysosome, for execution of degradation [15-17]. After 
digesting cargo, EL becomes lysosome (L) with evenly distributed content. The lyso-some is then recycled to fuse with LE again for the next round of the degradation process [15-17].

Inactivation of NSF ATPase affects mainly the Golgi-LE- lysosomal axis, probably because Golgi and LE are two of the most dynamic membrane-trafficking structures in a normal cell [15-17]. LE is the precursor of lysosome, and thus contains all lysosomal proteins such as cathepsins and lysosome-associated membrane protein-1/2 (LAMP1/2). For that reason, there is no single marker protein to identify lysosome [16, 17]. However, when LE fuses with lysosome, Vti1b, Rab7, and M6PR (LE SNAREs) are removed from the lysosomal membrane. Hence, Vti1b, Rab7, and M6PR are potential LE markers. Structures immunostaining positive for cathepsins or LAMP1/2, but negative for Vti1b, Rab7, and M6PR, may be identified as lysosomes [10, 16, 17].

Although dysfunction of the membrane-trafficking activities is a hallmark of most neurodegenerative disorders [9], it has not been studied after transient cerebral ischemia. The objective of this study is to investigate the role of the membrane-trafficking events after transient cerebral ischemia. The results demonstrate that the Golgi-LE-lysosome membrane-trafficking pathway is selectively damaged because of inactivation of NSF, resulting in a cascade of events of fatal release of cathepsin B (CTSB) and delayed neuronal death after $20 \mathrm{~min}$ of transient cerebral ischemia.

\section{Materials and Methods}

\section{Materials}

Leupeptin, pepstain, aprotinin, phenylmethylsulfonyl fluoride (PMSF), dithiothreitol (DTT), Triton X-100 (TX100 or Triton), sodium dodecyl sulfate (SDS), propidium iodide, and other chemicals were purchased from Sigma (Sigma, St. Louis, MO, USA). Rabbit monoclonal antibodies for confocal microscopy: anti-CTSB (Cat. \#31718, 1:500 dilution), anti-NeuN (Cat. \#24307, 1:500 dilution), and anti-beta-actin (Cat \#4970, 1:500 dilution) were purchased from Cell Signaling Tech (CST, Danvers, MA, USA). Mouse monoclonal antiTGN38 (Cat. \#610898, 1:100 dilution) and anti-Vti1b (Cat. \#611404, 1:300 dilution) were purchased from BD Transduction Laboratories. Mouse monoclonal anti-CTSB antibody (clone 3E4, 1:20 dilution) is generously provided by Dr. Ekkehard Weber (Institute for Physiological Chemistry, Martin Luther University of Halle-Wittenberg, Germany). The anti-mouse or anti-rabbit secondary antibodies were purchased from Jackson ImmunoResearch (PA, USA).

\section{Ischemia Model}

The 2-vessel occlusion (2-VO) rat transient cerebral or global ischemia model was produced by occlusion of two common carotid arteries while induction of hypotension as described previously [5,7]. All the experimental procedures were approved by the Animal Use and Care Committee in the University of Maryland School of Medicine. Briefly, male Wistar rats (about $300 \mathrm{~g}$ ) were fasted overnight and anesthetized with isoflurane. Catheters were inserted into the external jugular vein and tail artery to allow blood withdrawing (to induce hypotension), blood sampling (to measure blood gases) and mean arterial blood pressure 
(MABP) recording. A neck incision was made and both common carotid arteries were isolated and encircled by loose ligatures. Blood gases were measured and adjusted to $\mathrm{PaO} 2$ $>90 \mathrm{mmHg}, \mathrm{PaCO} 235-45 \mathrm{mmHg}$, and $\mathrm{pH}$ 7.35-7.45 during the intubation period. Brain temperature was maintained with a feedback heating lamp setting at $37^{\circ} \mathrm{C}$ during the surgical period until the rat recovered from anesthesia. Heparin $(150 \mathrm{IU} / \mathrm{kg})$ was administered i.v. and blood was withdrawn via the jugular catheter to produce a MABP of $45 \mathrm{mmHg}$, and both carotid arteries were clamped. MABP was maintained at $45 \mathrm{mmHg}$ during the ischemic period by withdrawing or infusing blood through the jugular catheter. At the end of the ischemic period, the clamps were removed and the blood reinfused through the jugular catheter, followed by $0.5 \mathrm{ml}$ of $0.6 \mathrm{M}$ sodium bicarbonate. For the $30 \mathrm{~min}$ reperfusion group, isoflurane was continued and brains were collected at $30 \mathrm{~min}$ after the end of the ischemia. For groups with reperfusion periods longer than $30 \mathrm{~min}$, isoflurane was discontinued at the end of ischemia, all wounds were sutured, and animals were returned to their cages. Sham-operated rats were subjected to the same surgical procedures but without induction of transient cerebral ischemia.

Three series of sham-operated control rats and rats subjected to $20 \mathrm{~min}$ of ischemia followed by $0.5,4,24$, or $72 \mathrm{~h}$ of reperfusion were prepared, respectively, for biochemical, histopathological or confocal microscopic, and electron microscopic (EM) studies. Based on the preliminary and previous studies, we performed a sample size estimate with a power of 0.80 , indicating that there is at least an $80 \%$ chance of detecting a difference among groups when more than four animals in each experimental group were used. Therefore, at least four rats were used in each experimental group. For biochemical analysis, brains were frozen in situ with liquid nitrogen while the animals were artificially ventilated [18]. The brains were isolated and brain subregions of the coronal planes were dissected in a $-12{ }^{\circ} \mathrm{C}$ glove box. For histopathology and confocal microscopy, rats were perfusion-fixed via ascending aorta with ice-cold $4 \%$ paraformal-dehyde in phosphate-buffered saline (PBS), sectioned with a vibratome, and stored in an anti-freeze solution at $-20{ }^{\circ} \mathrm{C}$ until use. For EM, rats were perfusion-fixed with ice-cold $2 \%$ para-formaldehyde and $2.5 \%$ glutaraldehyde in $0.1 \mathrm{M}$ cacodylate buffer according to the method of previous studies [5-8].

\section{Histopathology}

Animals were randomly assigned to the group prior to the surgical procedure. This study was conducted blindly. For histopathology, 10- $\mu \mathrm{m}$ paraffin section were stained with acid fuchsin and celestine blue and examined by light microscopy. For quantitative analysis of neuronal death, normal or survival neurons were counted using $50-\mu \mathrm{m}$ vibratome brain sections stained with hematoxylin and eosin (H\&E) at bregma $-3.60 \mathrm{~mm}$ of the hippocampal level, and the StereoInvestigator program and a custom-designed morphology and stereology software (MBF Bioscience, VT, USA). The computer controls the stage to randomly place the counting frame on the first counting area, and then to systematically move it until the entire delineated field is sampled. Cell numbers were quantified according to the optical fractionator method [19]. Only cells on the top layer of tissue sections between 4 and $14 \mu \mathrm{m}$ were counted. The extent of injury was expressed as percentage of dead (= sham-operated control brain section - ischemic brain section) among the total (dead + normal) neurons in the region examined (mean $+/-$ SEM, $n=4$ ). 


\section{Confocal Microscopy and Electron Microscopy}

For confocal microscopy, double-immunolabeling fluorescence confocal microscopy was performed using coronal brain sections $(50 \mu \mathrm{m})$ according to the method described in our previous studies [5-8]. For EM, brain tissue sections were stained by conventional osmiumuranyl-lead also as described previously [5-8]. Briefly, brains after perfusion-fixation were sectioned with a vibratome at $100 \mu \mathrm{m}$, post-fixed for $2 \mathrm{~h}$ in $1 \%$ osmium tetroxide in $0.1 \mathrm{M}$ cacodylate buffer immediately, rinsed in distilled water, and stained with $1 \%$ aqueous uranyl acetate overnight. The brain tissue sections were then dehydrated in an ascending series of ethanol to $100 \%$ followed by dry acetone and embedded in Durcupan ACM. Sections were then embedded in Durcopan ACM. Ultrathin sections $(0.1 \mu \mathrm{m})$ were prepared for EM examination.

\section{Preparation of Subcellular Fractions}

The rat dorsal-lateral neocortical $(\mathrm{Cx})$ tissue samples between the bregma 2.16 and $-4.8 \mathrm{~mm}$ and above the rhinal fissure mark were dissected and chopped into small pieces in a $-12{ }^{\circ} \mathrm{C}$ glove box freezer [5-8]. Each tissue sample obtained from a given rat was homogenized with a Dounce homogenizer (25 strokes) in 10 vol. of ice-cold homogenization buffer containing $15 \mathrm{mM}$ Tris base/HCl pH 7.6, $1 \mathrm{mM}$ DTT, $0.25 \mathrm{M}$ sucrose, $1 \mathrm{mM} \mathrm{MgCl} 2,1$ $\mu \mathrm{g} / \mathrm{ml}$ pepstain A, $5 \mu \mathrm{g} / \mathrm{ml}$ leupeptin, $2.5 \mu \mathrm{g} / \mathrm{ml}$ aproptonin, $0.5 \mathrm{mM}$ PMSF, $2.5 \mathrm{mM}$ EDTA, $1 \mathrm{mM}$ EGTA, $0.25 \mathrm{M} \mathrm{Na} 3 \mathrm{VO} 4,25 \mathrm{mM} \mathrm{NaF}$, and $2 \mathrm{mM}$ sodium pyrophosphate. Part of the homogenate $(\mathrm{H})$ was directly collected for Western blot analysis, and the rest was further centrifuged at $10,000 \mathrm{~g}$ at $4{ }^{\circ} \mathrm{C}$ for $10 \mathrm{~min}$ to obtain a pellet designated as $\mathrm{P}(1+2)$ and a supernatant fraction. The $\mathrm{P}(1+2)$ was named because it contains the conventional P1 ( $800 \mathrm{~g}$ homogenate pellet) and P2 (1000 g S1 pellet) [5-8]. The supernatant was further centrifuged at $165,000 \mathrm{~g}$ at $4{ }^{\circ} \mathrm{C}$ for $1 \mathrm{~h}$ to get a cytosolic fraction (S3) and an intracellular microsomal membrane fraction (P3) containing endoplasmic reticulum (ER), Golgi, and endosomal structures, as well as cytoskeletal proteins. The $10,000 \mathrm{~g} \mathrm{P}(1+2)$ pellet was suspended with ice-cold homogenization buffer containing $2 \%$ TX100 and $500 \mathrm{mM} \mathrm{KCl}$, sonicated 3 times $10 \mathrm{~s}$, washed on a shaker for $1 \mathrm{~h}$ at $4{ }^{\circ} \mathrm{C}$, and then centrifuged at $10,000 \mathrm{~g}$ for $10 \mathrm{~min}$ to obtain the detergent-salt insoluble pellet designated as $\mathrm{P}(1+2)$ p. Protein concentration was determined by the micro-bicinchoninic acid (BCA) method of Pierer (Rockford, USA).

\section{Western Blot Analysis}

Equal protein amounts among subcellular fraction samples were electrophoresed on 8 or $10 \%$ sodium dodecyl sulfate-polyacrylamide gels (SDS-PAGE) and then transferred to Immobilon-P membranes (Millipore, Billerica, MA, USA) according to the method described previously [5-8]. In addition to loading of the same protein amounts per subcellular fraction sample to every lane on SDS-PAGE, $\beta$-actin levels on immunoblots were used as an internal sample loading control. All Western blot data were normalized to $\beta$ actin data and expressed as the ratio between protein of interest and the $\beta$-actin protein level. Densitometry was performed with the ImageJ software (version 1.48, National Institutes of Health). 


\section{Statistical Analysis}

Data are expressed as mean \pm standard error of the mean (SEM). Four animals in each experimental group were employed for quantitative analysis of histopathology, and the densities of the protein bands on Western blots. One-way ANOVA followed by Tukey's posthoc tests were used for statistical analysis, ${ }^{*} p<0.05$ and ${ }^{* *} p<0.01$ between sham-operated control and post-ischemic groups.

\section{Results \\ Histopathology}

Twenty minutes of transient cerebral ischemia followed by reperfusion in the $2 \mathrm{VO}$ animal cerebral or global brain ischemia model used in this study leads to delayed neuronal death that occurs mainly at 2-3 days of reperfusion following the initial ischemic episode [19]. Figure 1 shows an example of light microscopic micrographs of histologically stained $\mathrm{Cx}$ layer 3 pyramidal neurons from a sham-operated control rat and a rat subjected to $20 \mathrm{~min}$ of cerebral ischemia followed by 3 days of reperfusion. Normal neuronal nuclei were round in shape and with a clear visible apical dendritic truck and nucleolus (Fig. 1a, b, arrows). The nuclei of dead neurons were significantly shrunken, became polygonal in shape, and surrounded with acidophilic cytoplasm (Fig. 1b, arrowheads). Furthermore, significant proliferation of elongated non-neuronal cells, probably activated microglial cells, was seen in the $\mathrm{Cx}$ regions (Fig. 1b, double arrows). Because some dead neurons might be removed after ischemia, we counted the numbers of normal or survival neurons, and then calculated dead neuron by subtracting the post-ischemic survival neurons from the sham normal neurons in the same region examined. Selective neuronal death occurs densely in more than $50 \%$ of Cx layers 3 and 5 pyramidal neurons at $72 \mathrm{~h}$ of reperfusion after $20 \mathrm{~min}$ of transient cerebral ischemia. However, when all dorsal-lateral $\mathrm{Cx}$ (pyramidal + non-pyramidal) neurons were counted, only about $28 \%$ of $\mathrm{Cx}$ neurons were dead (see Fig. 1c). The sterological analysis of histologically stained brain sections at the bregma $-3.60 \mathrm{~mm}$ level showed that neuronal death occurred in less than $10 \%$ ofCA1, 13\% oftheCx (layers 1-6), and $13 \%$ ofDG neurons at $24 \mathrm{~h}$ of reperfusion following $20 \mathrm{~min}$ of cerebral ischemia (Fig. 1c). Neuronal death occurs mostly at $72 \mathrm{~h}$ of reperfusion in about $90 \%$ of CA1, $28 \%$ of $\mathrm{Cx}$ (layers 1-6), and $21 \%$ of DG neurons after 20 min of transient cerebral ischemia (Fig. 1c).

\section{EM Observation of Golgi Fragmentation and LE Buildup}

EM showed that the most prominent ultrastructural changes in Cx pyramidal neurons destined to undergo neuronal death after transient cerebral ischemia were massive accumulation of Golgi fragments (Gf), transport vesicles (TVs), and late endosomes (LEs) (Fig. 2). A sham-operated control Cx pyramidal neuron, stained with the osmium-uraniumlead, has normal Golgi $(\mathrm{G})$, rough endoplasmic reticulum (ER), polyribosome rosettes (arrows), mitochondria (M), and LE (inset) (Fig. 2a). However, a massive buildup of Golgi fragments (Fig. 2b, Gf), transport vesicles (TVs) (Fig. 2b, double arrows), and LEs (Fig. 2b, arrows), as well as accumulation of protein aggregates (Fig. 2b, white arrowheads), were observed in Cx pyramidal neurons after transient cerebral ischemia. Accumulation of EMvisible protein aggregates was seen mainly in pyramidal neurons destined to die after transient cerebral ischemia [5, 7]. The LE structures in the insets of Fig. 2a, b can be better 
viewed with a higher magnification of the EM micrographs shown in Fig. 2c, d. The LE from the sham-operated control Cx neuron typically has an intact lipid membrane and contains multi-vesicular structures (Fig. 2c, arrow). In comparison, the LE structure from the post-ischemic $\mathrm{Cx}$ neuron contains irregular-shaped structures and has a large membrane break or damage (Fig. 2d, triple arrows). Furthermore, the post-ischemic LE membrane is often associated with fluffy protein aggregates (Fig. 2d, arrowheads). These morphological changes are somewhat similar to those observed by EM in the cellular systems in which the NSF activity was deficient or membrane-trafficking activity was inhibited [12, 14, 20-22].

\section{Depletion of Intra-neuronal NSF}

Previous studies show that the NSF deficiency or membrane-trafficking dysfunction leads to a buildup of Golgi fragments, TVs, and LEs in cellular systems and in vivo [12,14,20-24]. To study whether the massive buildup of Golgi fragments, TVs, and LEs shown in Fig. 2 is owing to depletion of active NSF after transient cerebral ischemia, we doubleimmunolabeled $\mathrm{Cx}$ brain sections from a sham-operated control rat and a rat subjected to 20 min of cerebral ischemia followed by $24 \mathrm{~h}$ of reperfusion with the following: (a) NSF and trans-Golgi network protein 38 (TGN38) (b) antibodies, NSF and CTSB antibodies, and (c) NeuN and CTSB antibodies, and then examined by confocal laser scanning microscopy. The peri-nuclear and apical dendritic NSF immunostaining in sham control $\mathrm{Cx}$ neurons (Fig. 3a, sham control, red, arrows) was overlapped partially with the TGN38 immunostaining (Fig. 3a, sham control, green+red = yellow, arrowheads), suggesting that NSF protein was located mainly in the Golgi of sham-operated control Cx neurons. The dense NSF immunostaining was also seen in the neuropil (Fig. 3a, red, stars), which probably reflected presynaptic terminal NSF protein as the immunostain-ing was shown to be co-localized with a presynaptic marker synaptophysin [25]. The NSF immunostaining was completely depleted from some Cx pyramidal neuronal soma and dendritic trucks (Fig. 3a, sham vs. $24 \mathrm{~h}$ of reperfusion, arrows), but less affected in the neuropil region (Fig. 3, sham vs. $24 \mathrm{~h}$ of reperfusion, red, stars) at $24 \mathrm{~h}$ of reperfusion following $20 \mathrm{~min}$ of cerebral ischemia. TGN38 antibody stained tubular Golgi structures in sham-operated control (Fig. 3a, sham control, green, arrowheads). However, the tubular Golgi structures were completely fragmented into weakly immunostained small dots at $24 \mathrm{~h}$ of reperfusion in Cx pyramidal neurons in which NSF was completely depleted (Fig. 3a, $24 \mathrm{~h}$ of reperfusion, green, arrowheads). Most Cx pyramidal neurons with NSF depletion and Golgi fragmentation were probably still alive at $24 \mathrm{~h}$ of reperfusion (Fig. 3a, $24 \mathrm{~h}$ of reperfusion, arrows and arrowheads) as shown by their normal cell body size and shape, and by the morphology of the NeuN immunostaining (see Fig. 3c below).

Figure $3 \mathrm{~b}$ shows that the peri-nuclear and apical dendritic NSF immunostaining in sham control Cx neurons (Fig. 3b, sham control, red, arrows) was only weakly overlapped with CTSB immunostaining in the soma and apical dendrites (Fig. 3b, sham control, red, arrowheads). In addition to the complete depletion of NSF immunostaining (Fig. 3b, $24 \mathrm{~h}$ of reperfusion, arrows), the size, intensity, and number of CTSB-immunostained structures were dramatically increased at $24 \mathrm{~h}$ of reperfusion (Fig. 3b, $24 \mathrm{~h}$ of reperfusion, green, arrowheads). Moreover, the CTSB immunostaining was more evenly distributed in the cytoplasm (Fig. 3b, $24 \mathrm{~h}$ of reperfusion, green, arrowheads) in which NSF was completely 
depleted at $24 \mathrm{~h}$ of reperfusion. The increased even CTSB immunostaining was mainly located in the cytoplasm of Cx pyramidal neurons as shown in Fig. 3c double immunostaining of CTSB (green) with a neuronal marker NeuN (red) (arrows), suggesting that CTSB might be released into the cytoplasm at $24 \mathrm{~h}$ of reperfusion after transient cerebral ischemia.

Figure 4a shows the time course of the depletion of NSF immunostaining (red, arrows) in $\mathrm{Cx}, \mathrm{CA} 1$, and DG neurons from sham-operated control rats, and rats subjected to $20 \mathrm{~min}$ of cerebral ischemia followed by 4,24 , and $72 \mathrm{~h}$ of reperfusion. The NSF immunostaining was completely depleted during the period of $4-72 \mathrm{~h}$ of reperfusion (Fig. $4 \mathrm{a}, \mathrm{Cx}$ and CA1 panels, 4-72 h, red, arrows), which persists until delayed neuronal death occurred at $72 \mathrm{~h}$ of reperfusion in most CA1 and Cx pyramidal neurons following 20 min of cerebral ischemia (Fig. 4a, 72 h, Cx and CA1 panels, red, arrows). Dead neurons were significantly shrunken, became polygonal in shape, and lost both NSF and TGN38 immunostaining activities (Fig. 4a, $72 \mathrm{~h}, \mathrm{Cx}$ and CA1 panels, arrowheads). In contrast, NSF im-munostaining was less affected in surviving neurons such as those in the DG region (Fig. 4a, DG panels, red, arrows), and in the neuropil area after the same period of cerebral ischemia (Fig. 4a, red, stars). Similarly, TGN38-immunostained tubular Golgi network structures became completely fragmented during the period of 4-72 h of reperfusion (Fig. 4a, Cx and CA1 panels, 4-72 h, green, double arrows), which persists until delayed neuronal death occurred at $72 \mathrm{~h}$ of reperfusion in most CA1 and Cx pyramidal neurons (Fig. 4a, $72 \mathrm{~h}, \mathrm{Cx}$ and CA1 panels, green, arrows). The delayed neuronal death occurred in about $90 \% \mathrm{CA} 1,28 \%$ of $\mathrm{Cx}$ neurons, and some DG neurons mostly at $72 \mathrm{~h}$ of reperfusion after $20 \mathrm{~min}$ of cerebral ischemia (see Fig. 1c).

Depletion of intra-neuronal NSF can be better viewed via a higher magnification of a 24-h reperfused Cx neuron shown in the individual red (Fig. 4b, upper), green (Fig. 4b, middle), and a red + green combined (Fig. 4b, lower) imaging channel. NSF immunostaining was completely disappeared (Fig. 4b, upper, red, arrows), while TGN38 immunostaining was completely fragmented (Fig. 4b, middle, green, double arrows) from the peri-nuclear and apical dendritic areas of the $\mathrm{Cx}$ neuron at $24 \mathrm{~h}$ of reperfusion after 20 min of cerebral ischemia. The Fig. $4 \mathrm{~b}$ lower panel shows the combination of the upper red and middle green images.

\section{NSF Deposition into Protein Aggregates}

The disappearance of intra-neuronal NSF immunostaining may be either due to the net loss of NSF protein or because of NSF irreversible deposition into dense protein aggregates after $20 \mathrm{~min}$ of cerebral ischemia. To investigate NSF redistribution further, we prepared homogenate $(\mathrm{H})$, a detergent (Triton X100)-salt insoluble protein aggregate-containing fraction $[\mathrm{P}(1+2) \mathrm{p}]$, in-tracellular microsomal membrane fraction (P3), and cytosolic fraction (S3) using the tissue samples dissected from sham-operated control and postischemic subjects. Western blotting demonstrated that NSF protein band was not significantly altered in the homogenate and intracellular microsomal membrane fraction before $24 \mathrm{~h}$ of reperfusion, but significantly decreased at $72 \mathrm{~h}$ of reperfusion (Fig. $4 \mathrm{c}$, homogenate and intracellular membrane). In comparison with those in the ho-mogenate and 
intracellular microsomal membrane fraction, the NSF level was virtually depleted from the cytosolic S3 fraction, while concomitantly increased in the detergent-salt insoluble protein aggregate 7lsqb; $\mathrm{P}(1+2)$ p] fraction after transient cerebral ischemia (Fig. 4c, cytosol and Triton-Salt aggregates). The results suggested that reduction of NSF immuno-staining observed in Figs. 3 and 4 ( $a$ and $b$ ) was likely because NSF was trapped into detergent-salt insoluble inactive protein aggregates that form very dense structures in vivo and cannot be accessed by NSF antibody during immunostaining of brain sections [5-8, 25]. The decrease in the NSF level in the homogenate at $72 \mathrm{~h}$ of reperfusion (Fig. 4c) was probably because delayed neuronal death occurred in the pyramidal neurons after $20 \mathrm{~min}$ of cerebral ischemia (see Fig. 1).

\section{Confocal Microscopic Characterization of Golgi Fragmentation and CSTB Accumulation}

Previous studies show that NSF inactivation leads to Golgi fragmentation in cells [12, 14, 20-24]. Confocal microscopic Golgi images were significantly different between pyramidal and non-pyramidal neurons [26]. To study the Golgi morphologies after $20 \mathrm{~min}$ of cerebral ischemia, we double-immunostained brain sections with TGN38 and CTSB antibodies, and then imaged the immunostaining with confocal microscopy (Fig. 5). The identification of pyramidal neurons was based on the conic-shaped soma and the presence of apical dendrites. In a sham Cx pyramidal neuron, confocal microscopic images of TGN38-immunostained Golgi showed the twisted tubular network structures that were densely distributed throughout the somata and apical dendrite (Fig. 5a, sham Cx, green, arrow), while CTSB immunostaining showed small dots (Fig. 5a, sham Cx, red, arrowhead). The twisted tubular Golgi network morphologies were completely fragmented into dots of various sizes (e.g., Fig. 5a, $24 \mathrm{~h} \mathrm{Cx}$, green, arrow), while CTSB-immunostained dots become considerably larger, more numerous, and evenly distributed in a 24-h reperfused $\mathrm{Cx}$ pyramidal neuron after 20 min of cerebral ischemia (e.g., Fig. 5a, 24 h Cx, red, arrowhead). The time-course study showed that TGN38-immunostained tubular Golgi networks were mostly fragmented in $\mathrm{Cx}$ and CA1 pyramidal neurons during the period of 4-72 $\mathrm{h}$ of reperfusion after $20 \mathrm{~min}$ of transient cerebral ischemia (Fig. 5a, Cx and CA1 panels, 4-72 h, green). Moreover, the TGN38 immuno-staining intensity was dramatically reduced in the $\mathrm{Cx}$ and CA1 pyramidal neurons during the reperfusion periods (Fig. 5a, Cx and CA1, 4-72 h, green, arrow). In comparison with pyramidal neurons, TGN38 immunostaining appeared as small rod- or donut-like structures in non-pyramidal neurons such as DG granule cells of sham-operated control rats (Fig. 5a, DG panels, sham, green, arrow). Although TGN38 immunostaining appeared a little weaker in 4- and 24-h reperfused brain sections than in the sham-operated control, the morphology of the rod- and donut-like Golgi structures appeared not obviously altered after $20 \mathrm{~min}$ of cerebral ischemia (Fig. 5a, DG panels, 4-72 h, green, arrow).

In comparison with TGN38 immunostaining, CTSB immunostaining was markedly increased both in size and intensity in Cx and CA1 pyramidal neurons (Fig. 5a, Cx and CA1 panels, 4-72 h, red), in which TGN38-immunostained Golgi structures were completely fragmented (Fig. 5a, Cx and CA1 panels, 4- $72 \mathrm{~h}$, green, arrows). Moreover, CTSB immunostaining became evenly or diffusely distributed in the cytoplasm of the $\mathrm{Cx}$ and CA1 pyramidal neurons at $24 \mathrm{~h}$ of reperfusion (Fig. 5a, Cx and CA1 panels, $24 \mathrm{~h}$, red), suggesting 
that CTSB might be released into the cytoplasm before delayed neuronal death occurred at 3 days of reperfusion after transient cerebral ischemia.

Western blotting further demonstrated that TGN38 was not altered in the homogenate and intracellular microsomal membrane (P3) fraction, but significantly decreased in the cytosolic fraction while concomitantly deposited into the detergent-salt insoluble aggregate fraction before $24 \mathrm{~h}$ of reperfusion (Fig. 5b). Therefore, similar to that of NSF, the reduction of TGN38 immunostaining intensity shown in Fig. 5a was probably owing to the deposition of TGN38 into inactive protein aggregates after transient cerebral ischemia. The TGN38 protein levels tended to decrease generally in subcellular fractions at $72 \mathrm{~h}$ of reperfusion (Fig. 5b), probably because delayed neuronal death occurred in neurons after $20 \mathrm{~min}$ of transient cerebral ischemia (see Fig. 1).

\section{Release of 33 kDa LE CTSB After 20 min of Cerebral Ischemia}

The changes in CTSB immunostaining from small dots of the sham control to the enlarged structures or even distribution in the post-ischemic neurons throughout the cytoplasm shown in Figs. 3b and 5a may be owing to the release of CTSB into the cytoplasm after $20 \mathrm{~min}$ of cerebral ischemia. To study this further, we performed Western blot analysis to study changes in the CTSB levels over time during the reperfusion periods (Fig. 6). There are three forms of CTSB: (i) $46 \mathrm{kDa}$ proCTSB located in Golgi and TVs, (ii) $33 \mathrm{kDa}$ CTSB in LE, and (iii) 24-25 kDa CTSB in lysosomes [27]. CTSB is delivered from Golgi to LEs and then from LE to lysosome via the NSF-dependent machinery [10, 15, 27-29]. Hence, NSF inactivation may lead to disruption of the transport of $33 \mathrm{kDa}$ from LE to lysosome, resulting in a buildup of $33 \mathrm{kDa}$ LE CTSB with a corresponding reduction of $24-25 \mathrm{kDa}$ lysosomal CTSB. Also, the $46 \mathrm{kDa}$ proCTSB can autocleave itself to become a (mature) 33 $\mathrm{kDa}$ LE CTSB [27-29]. Figure 6 shows that only $33 \mathrm{kDa}$ LE CTSB is significantly increased (Fig. 6a) while $46 \mathrm{kDa}$ Golgi proCTSB is correspondingly decreased in the cytosolic and Golgi-containing intracellular microsomal membrane (P3) fractions (Fig. 6b) after transient cerebral ischemia. Moreover, the $24-25 \mathrm{kDa}$ lysosomal CTSB was also reduced significantly in the intracellular microsomal membrane fraction (containing Golgi and LE structures) (Fig. 6c, intracellular membrane), probably due to the deficiency of CTSB delivery from LE to lyso-some. The 24-25 kDa lysosomal CTSB was increased in the detergent-salt insoluble fraction (Fig. 6c, Triton-Salt aggregates), suggesting that some lysosomes might be associated with protein aggregates and thus deposited into the detergentsalt insoluble fraction after transient cerebral ischemia.

Increase only in the $33 \mathrm{kDa}$ LE form of CTSB after transient cerebral ischemia may indicate that CTSB is released from LE. To study this further, we double-immunolabeled brain sections from sham-operated control rats and rats subjected to $20 \mathrm{~min}$ of transient cerebral ischemia followed by 4,24 , and $72 \mathrm{~h}$ of reperfusion with antibody against an LE protein marker Vtilb (vesicle transport through interaction with t-SNAREs homolog 1b) and antibody to CTSB (Fig. 7a). In sham-operated control brain sections, CTSB (red) and Vtilb (green) antibodies immunostained only a few common dots but mostly different dots in $\mathrm{Cx}$ and CA1 pyramidal neurons (Fig. 7a, arrows). In comparison with those in sham control brain sections, in post-ischemic brain sections, the level of CTSB immunostaining (red) was 
progressively increased while the level of Vtilb immunostaining (green) was gradually decreased in Cx and CA1 pyramidal neurons before $24 \mathrm{~h}$ of reperfusion (Fig. 7a, arrows). Moreover, CTSB immunostaining pattern (red) was changed from dot-like structures to diffuse or even distribution throughout the cytoplasm especially at $24 \mathrm{~h}$ of reperfusion (Fig. 7a, Cx and CA1 panels, sham vs. $24 \mathrm{~h}$, red, arrows), suggesting that CTSB might indeed be released from the Vtilb-immunostained LEs to the cytoplasm after transient cerebral ischemia. At $72 \mathrm{~h}$ of reperfusion, many $\mathrm{Cx}$ and most CA1 pyramidal neurons were dead and revealed polygonally shaped morphologies (Fig. 7a, 72 h, Cx and CA1 panels, arrowheads). In comparison with those in $\mathrm{Cx}$ and $\mathrm{CA} 1$ regions, the morphologies of both Vti1 b and CTSB immunostaining patterns in survival neurons such as those in the DG area were not significantly altered after 20 min of cerebral ischemia (Fig. 7a, sham - 72 h, DG, arrows).

Western blot analysis further revealed that the Vtilb protein level tended to increase in the homogenate, and was significantly increased in the intracellular microsomal membrane and Triton-salt insoluble protein aggregate fraction during the period of $0.5-24 \mathrm{~h}$ of reperfusion (Fig. 7b). The results suggest that the membrane trafficking from LE to lysosome may be interrupted, resulting in buildup of Vti1b protein in the LE membrane, probably as a result of NSF inactivation after transient cerebral ischemia. The Vtilb protein level was not changed in the cytosolic S3 during $0.5-24 \mathrm{~h}$ of reperfusion (Fig. 7b). At $72 \mathrm{~h}$ of reperfusion, the Vtilb protein levels generally tended to reduce in all subcellular fractions, probably because neuronal death occurred in many neurons after $20 \mathrm{~min}$ of cerebral ischemia.

\section{Discussion}

Twenty minutes of transient cerebral ischemia leads to delayed neuronal death selectively in pyramidal neurons of hippocampal CA1 and layers 3 and $5 \mathrm{Cx}$ regions, whereas neurons in other regions such as those in the DG area are relatively resistant to the same ischemic episode [1-5]. The search for mechanisms underlying delayed neuronal death after transient cerebral ischemia has been extensive, but they are still incompletely understood. The results of the present study support a novel hypothesis that NSF inactivation leads to a massive buildup of damaged Golgi, TV, and LE organelles, resulting in fatal CTSB release and delayed neuronal death after transient cerebral ischemia.

\section{Depletion of Intra-neuronal NSFAfter Transient Cerebral Ischemia}

This study shows that the NSF protein is virtually completely depleted from the cytoplasm and deposited into the detergent-salt insoluble aggregates in hippocampal CA1 and Cx pyramidal neurons after $20 \mathrm{~min}$ of transient cerebral ischemia. In several cell culture and cell-free systems, as well as in an in vivo drosophila model, NSF ATPase deficient mutation or inhibition of NSF ATPase activity leads to inactive deposition of NSF protein into Triton X100-insoluble protein aggregates. This brings the intracellular membrane-trafficking activities into a halt, resulting in cell death [25, 30,31]. By analogy, complete inactivation of NSF ATPase is likely to interrupt the intracellular membrane-trafficking activities and to contribute to the delayed neuronal death after transient cerebral ischemia.

Most excitatory pyramidal neurons have numerous axonal terminals and dendritic branches with an extremely large surface membrane area, and thus require extraordinary levels of 
membrane-trafficking activities. This may explain why NSF is more concentrated in pyramidal neurons (Fig. 3). The tissues of the central nervous system express the highest levels of NSF gene [32]. The underlying mechanism for depletion of intra-neuronal NSF and inactive deposition of NSF into the Triton-salt insoluble protein aggregates after transient cerebral ischemia remains elusive. Previous studies show that neurons containing EMvisible protein aggregates during the reperfusion period will eventually undergo delayed neuronal death after transient cerebral ischemia [5-8]. The present study shows that the massive buildup of Golgi fragments, TVs, and LEs are always associated with the EMvisible protein aggregates in hippocampal CA1 and Cx pyramidal neurons after transient cerebral ischemia (Figs. 2, 3, 4, 5, 6, and 7). Evidence strongly suggests that membranetrafficking activities are severely and persistently damaged mainly in post-ischemic neurons destined to die after transient cerebral ischemia.

Previous studies also demonstrate that newly or partially synthesized peptide chains, also known as nascent peptide chains (NPCs), are major components of the intra-neuronal protein aggregates after transient cerebral ischemia [5-8]. NPCs refer to those that are still being synthesized on ribosomes, being transported in or on the TVs, being assembled to their destined organelles or cell membranes, or being secreted into the extracellular space. Membranous and secreted NPCs are distributed via the Golgi and Golgi-derived TVs, and degraded via the LE-lysosomal system. NPCs expose their sticky hydrophobic segments during transportation and assembly, are highly prone to aggregation, and thus must be protected by molecular chaper-ones in a normal neuron [5-8]. Transient cerebral ischemia impairs molecular chaperones, resulting in accumulation of unprotected NPCs that may trap NSF, TGN38, and Vtilb into the aggregates [5-8]. This explanation is consistent with the observation that protein aggregates are always closely associated with Golgi fragments, TVs, and LEs in neurons destined to die after transient cerebral ischemia [5-8]. Similarly, progressive accumulation of intra-neuronal phosphotau protein aggregates is associated with buildup of Golgi fragments and reduction of Golgi surface area in the hippocampal brain sections of Alzheimer's disease patients [26]. Evidence suggests that the massive buildup of Golgi fragments, TVs, LEs, and protein aggregates in pyramidal neurons is an early sign of upcoming delayed neuronal death after transient cerebral ischemia.

\section{NSF Inactivation Preferentially Affects the Golgi-LE- Lysosome Trafficking Pathway}

The Golgi and LE are two of the most dynamic NSF ATPase-dependent subcellular organelles, and undergo significantly morphological and biochemical changes in response to different pathological conditions [33-37]. Confocal laser scanning microscopy is able to view the Golgi or LE structures with an acceptable resolution. Furthermore, relative to EM that can view only a limited area of a specimen, confocal microscopy is able to examine organelle markers in the entire brain sections (Figs. 3, 4, 5, and 7). The double-

immunostaining confocal microscopy with Golgi marker TGN38, and LE markers Vti1b or CTSB (Figs. 3, 5, and 7), confirmed the EM observation (Fig. 2) of the massive buildup of Golgi fragments and LEs in the entire sector of the hippocampal CA1 and most of layers 3 and 5 pyramidal neurons destined to die after $20 \mathrm{~min}$ of transient cerebral ischemia. 
The biochemical analyses show that key proteins related to the Golgi-LE-lysosome membrane-trafficking pathway (including NSF, TGN38, CTSB, and Vti1b) are irreversibly deposited into the detergent-salt insoluble aggregates after $20 \mathrm{~min}$ of cerebral ischemia (Figs. 4, 5, 6, and 7). Expression of an LE SNARE activity-deficient mutant in cultured cells interferes mainly with the LE-to-lysosome trafficking, but has minor effects on other subcellular structures, such as the ER and mitochondria [13-17]. In cultured cells or cellfree systems, inacti-vation of either NSF or the SNAREs leads to a massive buildup of Golgi fragments, TVs and enlarged LEs [10, 14, 15, 21, 30, 34, 35]. Expression of an activitydeficient mutant of syntaxin 11 (an endosomal SNARE protein) inhibits the late endosome to lysosome fusion in macrophages, resulting in an accumulation of enlarged LEs [15]. Evidence supports the notion that NSF inactivation may preferentially affect the Golgi-LElyso-some trafficking pathway after transient cerebral ischemia.

Selective Release $33 \mathrm{kDa}$ LE CTSB After Transient Cerebral Ischemia The following lines of evidence suggest that CTSB may be released from massively accumulated Golgi, TVs, and LEs after transient cerebral ischemia. First, the Golgi-LE- lysosomal trafficking is the most active type of membrane-trafficking activities [13-17]. NSF inactivation may preferentially disrupt the LE-to-lysosome fusion, thus trapping lysosomal enzymes inside Golgi, TV, and LE structures without further delivery to the lysosome [13-17, 33-37]. Perhaps, the most damaging molecules trapped inside these structures are cathepsin proteases. Relative to other cathepsins, CTSB shows the highest level of expression in neurons [38]. The present study clearly shows that $33 \mathrm{kDa}$ CTSB is significantly increased in the cytosolic S3 and intracellular microsomal membrane P3 fraction (Fig. 6a), suggesting that $33 \mathrm{kDa}$ CTSB is released into the cytoplasm of neurons after transient cerebral ischemia. When the $46 \mathrm{kDa}$ proCTSB is trapped inside the Golgi and TVs, it can autocleave its own propeptide to become a $33 \mathrm{kDa}$ LE CTSB [29]. This is supported by the present study showing that $20 \mathrm{~min}$ of transient cerebral ischemia leads to a significant reduction of the $46 \mathrm{kDa}$ proCTSB (Fig. 6b) while a corresponding increasein $33 \mathrm{kDa}$ LE CTSB in the Golgi-containing membrane P3 fraction (Fig. 6a). Second, the 24- $25 \mathrm{kDa}$ lysosomal CTSB is significantly decreased in the intracellular membrane $\mathrm{P} 3$ fraction after 20 min of transient cerebral ischemia (Fig. 6c), probably due to the disruption of CTSB delivery from LE to lysosome. For those reasons, $33 \mathrm{kDa}$ CTSB may be significantly accumulated in Golgi fragment, TV, and LE structures, and eventually leaked out from these structures into the cytoplasm (see Figs. 3b, 5, and 7). Release of $33 \mathrm{kDa}$ LE CTSB into the cytoplasm may further damage Golgi, TV, and LE structures, resulting in amplified release of $33 \mathrm{kDa}$ CTSB into the cytoplasm.

\section{Fatal CTSB Release Leads to Neuronal Death After Transient Cerebral Ischemia}

Previous studies show that moderate CTSB release activates the Bid-Bak or Bax pathway, resulting in induction of mitochondrial outer membrane permeabilization (MOMP) and cell death [39-44]. Bak is translationally repressed in mature neurons and thus its protein is not expressed under either normal or stress conditions [40], whereas both Bid and Bax are expressed in mature neurons [42-44]. MOMP has been detected in several paradigms of neuronal death and is commonly considered as the "point of no return" [40-43]. Extensive CTSB release, however, can digest proteins indiscriminately to directly induce cell death 
[43]. The present study (Fig. 6) shows that the cytosolic level of $33 \mathrm{kDa}$ CTSB is moderately increased prior to $24 \mathrm{~h}$ of reperfusion, but very dramatically increased at $72 \mathrm{~h}$ of reperfusion when neuronal death occurs after $20 \mathrm{~min}$ of transient cerebral ischemia. Evidence supports the notion that transient cerebral ischemia may lead to a moderate release of CTSB to activate the Bid-Bax pathway, which is followed by an extensive release of CTSB, resulting in delayed neuronal death in the larger population of pyramidal neurons during the period of 48-72 h of reperfusion after transient cerebral ischemia.

\section{Acknowledgments}

Funding This work was supported by National Institutes of Health (NIH) grants: NS36810, NS40407, and NS097875; by Veteran Affair Merit grant: I01BX001696; and by the American Heart Association 0940042N-5 to B.R.H.

\section{References}

1. Smith ML, Auer RN, Siesjo BK. The density and distribution of ischemic brain injury in the rat following 2-10 min of forebrain ischemia. Acta Neuropathol (Berl). 1984; 64:319-32. [PubMed: 6507048]

2. Wang W, Redecker C, Bidmon HJ, Witte OW. Delayed neuronal death and damage of GDNF family receptors in CA1 following focal cerebral ischemia. Brain Res. 2004; 1023:92-101. [PubMed: 15364023]

3. Horn M, Schlote W. Delayed neuronal death and delayed neuronal recovery in the human brain following global ischemia. Acta Neuropathol. 1992; 85:79-87. [PubMed: 1285498]

4. Kirino T, Sano K. Fine structural nature of delayed neuronal death following ischemia in the gerbil hippocampus. Acta Neuropathol. 1984; 62:209-18. [PubMed: 6695555]

5. Hu BR, Martone ME, Jones YZ, Liu CL. Protein aggregation after transient cerebral ischemia. The Journal of Neuroscience. 2000; 20:3191-1999. [PubMed: 10777783]

6. Hu BR, Janelidze S, Ginsberg MD, Busto R, Perez-Pinzon M, Sick TJ, et al. Protein aggregation after focal brain ischemia and reperfusion. J Cereb Blood Flow Metab. 2001; 21:865-75. [PubMed: 11435799]

7. Liu CL, Ge P, Zhang F, Hu BR. Co-translational protein aggregation after transient cerebral ischemia. Neurosci. 2005; 134:1273-84.

8. Zhang F, Liu CL, Hu BR. Irreversible aggregation of protein synthesis machinery after focal brain ischemia. J Neurochem. 2005; 98:102-12.

9. Wang D, Chan CC, Cherry S, Hiesinger PR. Membrane trafficking in neuronal maintenance and degeneration. Cell Mol Life Sci. 2013; 70(16):2919-34. [PubMed: 23132096]

10. Yuan D, Liu C, Hu B. Dysfunction of membrane trafficking leads to CTSB release and brain ischemia-reperfusion injury. Transl Stroke Res. 2017 in press.

11. Morgan A, Burgoyne RD. Is NSF a fusion protein? Trends Cell Biol. 1995; 5:335-9. [PubMed: 14732068]

12. Mohtashami M, Stewart BA, Boulianne GL, Trimble WS. Analysis of the mutant Drosophila Nethylmaleimide sensitive fusion-1 protein in comatose reveals molecular correlates of the behaviouralparalysis. J Neurochem. 2001; 77:1407-17. [PubMed: 11389191]

13. Robinson LJ, Aniento F, Gruenberg J. NSF is required for transport from early to late endosomes. J Cell Sci. 1997; 110:2079-87. [PubMed: 9378758]

14. Dalal, S., Rosser, MFN., Cyr, DM., Hanson, PI. Distinct Roles for the AAA ATPases NSF and p97 in the Secretory Pathway. In: Glick, B., editor. Mol Biol Cell. Vol. 15. 2004. p. 637-48.

15. Offenhauser C, Lei N, Roy S, Collins BM, Stow JL, Murray RZ. Syntaxin 11 binds Vti1b and regulates late endosome to lysosome fusion in macrophages. Traffic. 2011; 12:762-73. [PubMed: 21388490] 
16. Luzio JP, Gray SR, Bright NA. Endosome-lysosome fusion. Biochem Soc Trans. 2010; 38:1413-6. [PubMed: 21118098]

17. Kunwar AJ, Rickmann M, Backofen B, Browski SM, Rosenbusch J, Schöning S, et al. Lack of the endosomal SNAREs vtila and vtilb led to significant impairments in neuronal development. PNAS U S A. 2011; 108:2575-80.

18. Ponten U, Ratcheson RA, Salford L, Siesjö BK. Optimal freezing conditions for cerebral metabolites in rats. J Neurochem. 1973; 21:1127-38. [PubMed: 4761701]

19. Luo T, Roman P, Liu C, Sun X, Park Y, Hu B. Upregulation of the GEF-H1 Pathway after Transient Cerebral Ischemia. Experimental neurology. 2015; 263:306-13. [PubMed: 25447939]

20. Brunger AT. Structure of proteins involved in synaptic vesicle fusion in neurons. Annu Rev Biophys Biomol Struct. 2001; 30:157-1571. [PubMed: 11340056]

21. Malhotra V, Orci L, Glick BS, Block MR, Rothman JE. Role of an N-ethylmaleimide-sensitive transport component in promoting fusion of transport vesicles with cisternae of the Golgi stack. Cell. 1988; 54:221-7. [PubMed: 3390865]

22. May AP, Whiteheart SW, Weis WI. Unraveling the mechanism of the vesicle transport ATPase NSF, the N-ethylmaleimide-sensitive factor. J Biol Chem. 2001; 276:21,991-4.

23. Whiteheart SW, Matveeva EA. Multiple binding proteins suggest diverse functions for the Nethylmaleimide sensitive factor. J Struct Biol. 2004; 146:32-43. [PubMed: 15037235]

24. Brandon E, Szul T, Alvarez C, Grabski R, Benjamin R, Kawai R, et al. On and off membrane dynamics of the endoplasmic reticulum-golgi tethering factor p115 in vivo. Mol Biol Cell. 2006; 17:2996-3008. [PubMed: 16624868]

25. Liu CL, Hu BR. Alterations of N-Ethylmaleimide-Sensitive ATPase Following Transient Cerebral Ischemia. Neuroscience. 2004; 128:767-74. [PubMed: 15464284]

26. Antón-Fernández A, Aparicio-Torres G, Tapia S, DeFelipe J, Muñoz A. Morphometric alterations of Golgi apparatus in Alzheimer's disease are related to tau hyperphosphorylation. Neurobiol Dis. 2017; 97(Pt A):11-23. [PubMed: 27793637]

27. Turk V, Stoka V, Vasiljeva O, Renko M, Sun T, Turk B, et al. Cysteine cathepsins: from structure, function and regulation to new frontiers. Biochim Biophys Acta. 1824; 2012:68-88.

28. Huotari J, Helenius A. Endosome maturation. EMBO J. 2011; 30:3481-500. [PubMed: 21878991]

29. Pungercar JR, Caglic D, Sajid M, Dolinar M, Vasiljeva O, Pozgan U, et al. Autocatalytic processing of procathepsin B is triggered by proenzyme activity. The FEBS journal. 2009; 276:660-8. [PubMed: 19143833]

30. Block MR, Glick BS, Wilcox CA, Wieland FT, Rothman JE. Purification of an N-ethylmaleimidesensitive protein catalyzing vesicular transport. Proc Natl Acad Sci U S A. 1988; 85:7852-6. [PubMed: 3186695]

31. Hong HK, Chakravarti A, Takahashi JS. The gene for soluble N-ethylmaleimide sensitive factor attachment protein $\{$ alpha $\}$ is mutated in hydrocephaly with hop gait (hyh) mice. Proc Natl Acad Sci U S A. 2004; 101:1748-53. [PubMed: 14755058]

32. Https://gtexportal.org/home/gene/NSF

33. Diaz R, Mayorga LS, Weidman PJ, Rothman JE, Stahl PD. Vesicle fusion following receptormediated endocytosis requires a protein active in Golgi transport. Nature. 1989; 339:398-400. [PubMed: 2725659]

34. Wattenberg BW, Raub TJ, Hiebsch RR, Weidman PJ. The activity of Golgi transport vesicles depends on the presence of the N-ethylmaleimide-sensitive factor (NSF) and a soluble NSF attachment protein (alpha SNAP) during vesicle formation. J Cell Biol. 1992; 118:1321-32. [PubMed: 1522110]

35. Acharya U, Jacobs R, Peters JM, Watson N, Farquhar MG, Malhotra V. The formation of Golgi stacks from vesiculated Golgi membranes requires two distinct fusion events. Cell. 1995; 82:895904. [PubMed: 7553850]

36. Naslavsky N, McKenzie J, Altan-Bonnet N, Sheff D, Caplan S. EHD3 regulates early-endosometo-Golgi transport and preserves Golgi morphology. J Cell Sci. 2009; 122:389-400. [PubMed: 19139087] 
37. Mullock BM, Bright NA, Fearon CW, Gray SR, Luzio J. Fusion of Lysosomes with Late Endosomes Produces a Hybrid Organelle of Intermediate Density and Is NSF Dependent. J Cell Biol. 1998; 140(3):591-601. [PubMed: 9456319]

38. Petanceska S, Burke S, Watson SJ, Devi L. Differential distribution of messenger RNAs for cathepsins B, L and S in adult rat brain: an in situ hybridization study. Neuroscience. 1994; 59:729-38. [PubMed: 8008216]

39. Gómez-Sintes R, Ledesma MD, Boya P. Lysosomal cell death mechanisms in aging. Ageing Res Rev. 2016; 32:150-168. [PubMed: 26947122]

40. Repnik U, Stoka V, Turk V, Turk B. Lysosomes and lysosomal cathepsins in cell death. Biochim Biophys Acta. 1824; 2012:22-33.

41. Jakobson M, Jakobson M, Llano O, Palgi J, Arumäe U. Multiple mechanisms repress N-Bak mRNA translation in the healthy and apoptotic neurons. Cell Death Dis. 2013; 4:e777. [PubMed: 23969856]

42. Akhtar RS, Ness JM, Roth KA. Bcl-2 family regulation of neuronal development and neurodegeneration. Biochim Biophys Acta. 1644; 2004:189-203.

43. Serrano-Puebla A, Boya P. Lysosomal membrane permeabilization in cell death: new evidence and implications for health and disease. Ann N Y Acad Sci. 2016; 1371:30-44. [PubMed: 26599521]

44. Prunell GF, Mathiesen T, Svendgaard NA. Experimental subarachnoid hemorrhage: cerebral blood flow and brain metabolism during the acute phase in three different models in the rat. Neurosurgery. 2004; 54:426-36. [PubMed: 14744290]

\section{Abbreviations}

NSF N-ethylmaleimide sensitive factor ATPase

SNAREs Soluble NSF attachment protein receptors

SNAP Soluble NSF attachment protein

CTSB Cathepsin B

TVs Transport vesicles

LE Late endosome

EL Endolysosome

L Lysosome

MOMP Mitochondrial outer membrane permeabilization

IRI Ischemia-reperfusion injury

DG Dentate gyrus

EM Electron microscopy

Vti1b Vesicle transport through interaction with t-SNAREs homolog 1B

TGN38 Trans-Golgi network membrane protein $38 \mathrm{kDa}$ 

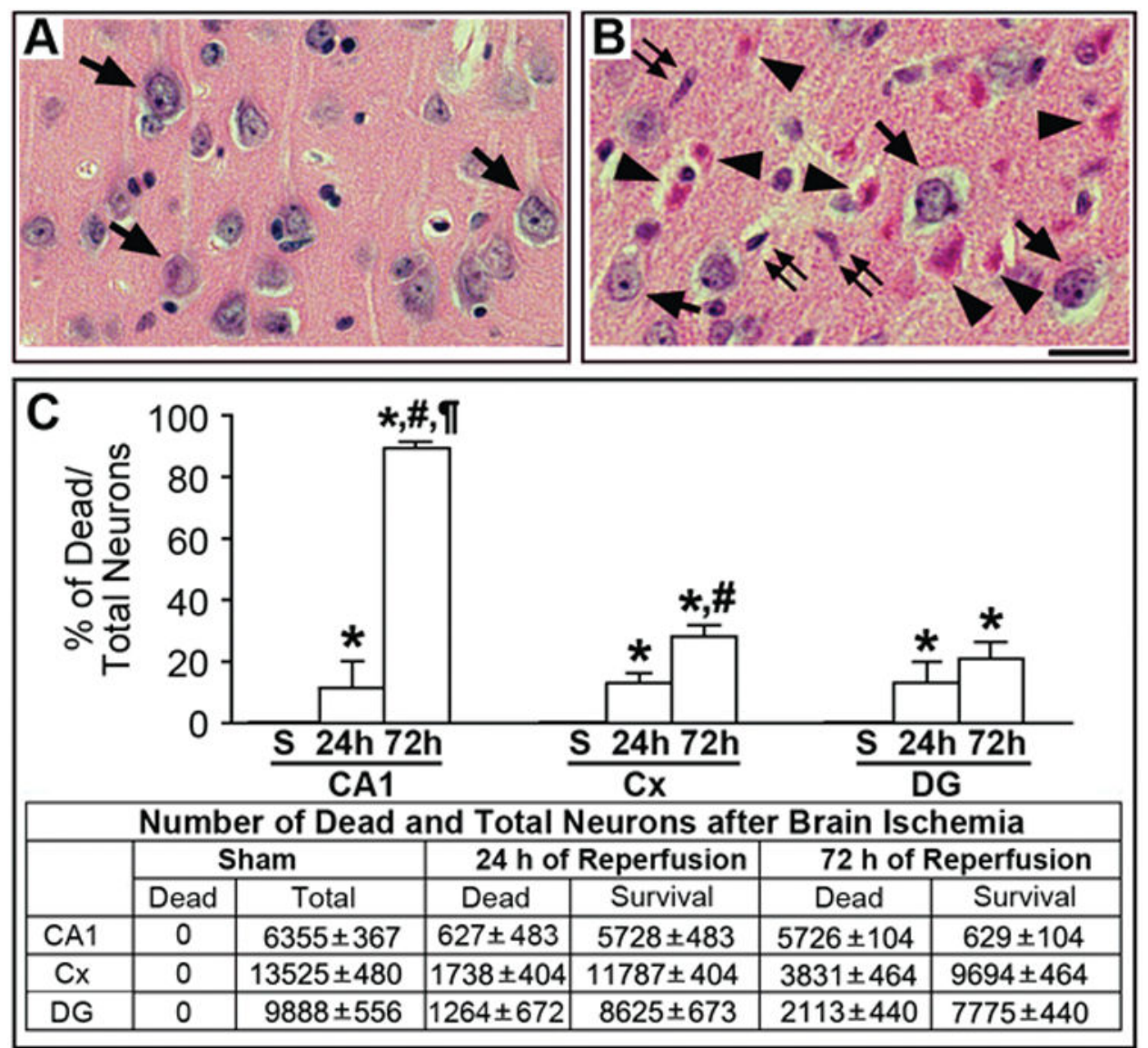

Fig. 1.

Histopathology. Neocortical (Cx) tissue sections were obtained from a sham-operated control rat and a rat subjected to 20 min of cerebral ischemia following by $72 \mathrm{~h}$ of reperfusion. a Sham-operated control neu-ronal nuclei in the Cx tissue section were round in shape and with visible nucleoli and apical dendritic trucks (arrows). b The nuclei of ischemic dead neurons in the Cx tissue section are significantly shrunken and with acidophilic cytoplasm (arrowheads). Significant proliferation of elongated non-neuronal cells was seen in the Cx tissue sections (double arrows). Arrows indicate survival neurons. c Quantification of dead and normal or survival neurons in the CA1, DG, and Cx with an unbiased stereology method (see Methods). The extent of injury was expressed as percentage of dead (= sham-operated control brain section - ischemic brain section) among the total (dead + normal) neurons in the region examined (mean $\pm \mathrm{SEM}, n=4$ ). ${ }^{*} p<0.05$, sham vs. post-ischemia; $\# p<0.05,72$ h vs. 24 h of reperfusion; Ip $<0.05$, CA1 vs. Cx and DG 


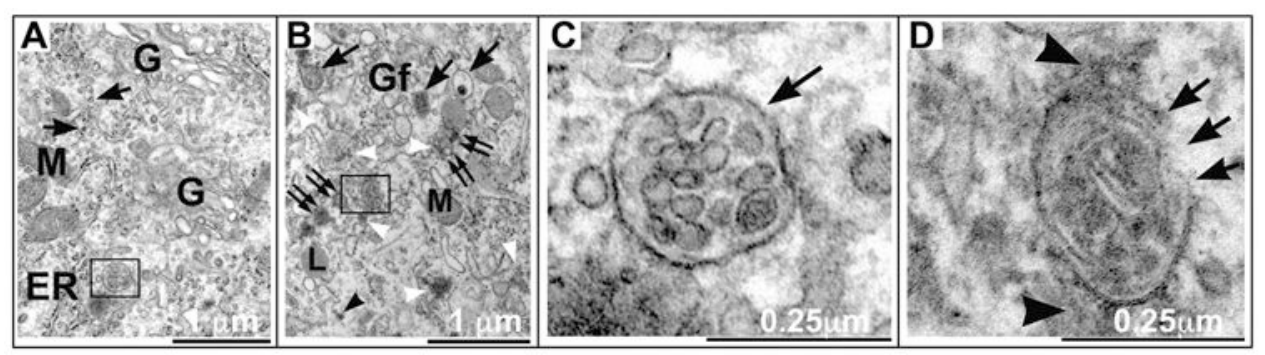

Fig. 2.

EM micrographs of Cx neurons. The Cx tissue sections were obtained from rats subjected to (non-ischemic) sham surgery or $20 \mathrm{~min}$ of cerebral ischemia followed by $24 \mathrm{~h}$ of reperfusion. a A sham neuron shows normal rough endoplasmic reticulum (ER), ribosomal rosettes (arrows), mitochondria (M), Golgi apparatus (G), and late endosome (LE). b A 24-h reperfused neuron shows accumulation of Golgi fragments (Gf), transport vesicles (double arrows), late endosome (arrows and inset), and ribosomal aggregates (white arrowheads). Scale bar $=1 \mu \mathrm{m}$. $\mathbf{c}$ and $\mathbf{d}$ Higher magnification of the insets of $\mathrm{a}$ and $\mathrm{b}$ shows that an LE (arrow) from the sham control neuron has intact lipid membrane, whereas an LE from the pos-tischemic neuron is associated with fluffy protein aggregates (arrowheads) and has a large membrane break (triple arrows). Scale bar $=0.25 \mu \mathrm{m}$ 

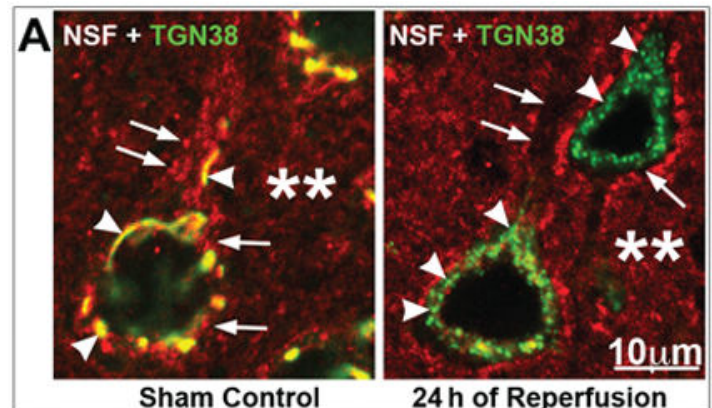

Sham Control

$24 \mathrm{~h}$ of Reperfusion
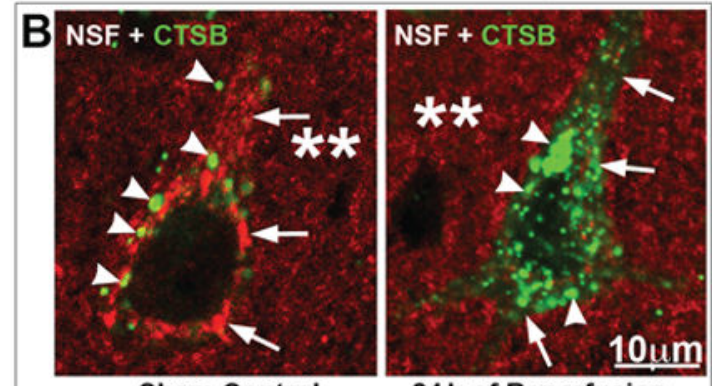

Sham Control

$24 \mathrm{~h}$ of Reperfusion

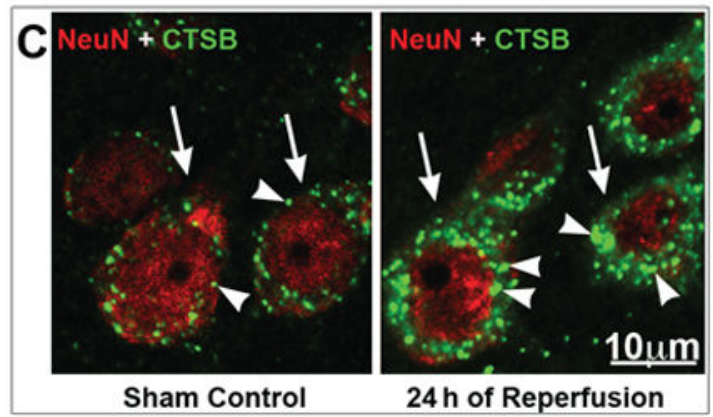

Fig. 3.

Confocal microscopic images of $\mathrm{Cx}$ neurons in brain sections from a sham-operated control rat and a rat subjected to $20 \mathrm{~min}$ of cerebral ischemia followed by $24 \mathrm{~h}$ of reperfusion. a NSF and trans-Golgi network protein 38 (TGN38) double immunostaining. Arrows indicate NSF im-munostaining (red), arrowheads point to TGN38 immunostaining (green), and stars denote the neuropil region. b NSF and CTSB double immunostaining. Arrows indicate NSF immunostaining (red), arrowheads point to CTSB immunostaining (green), and stars denote the neuropil region. $\mathbf{c}$ NeuN (red) and CTSB (green) doubleimmunostaining. Arrows indicate NeuN immunostaining (red). Arrowheads point to CTSB immunostaining (green) 


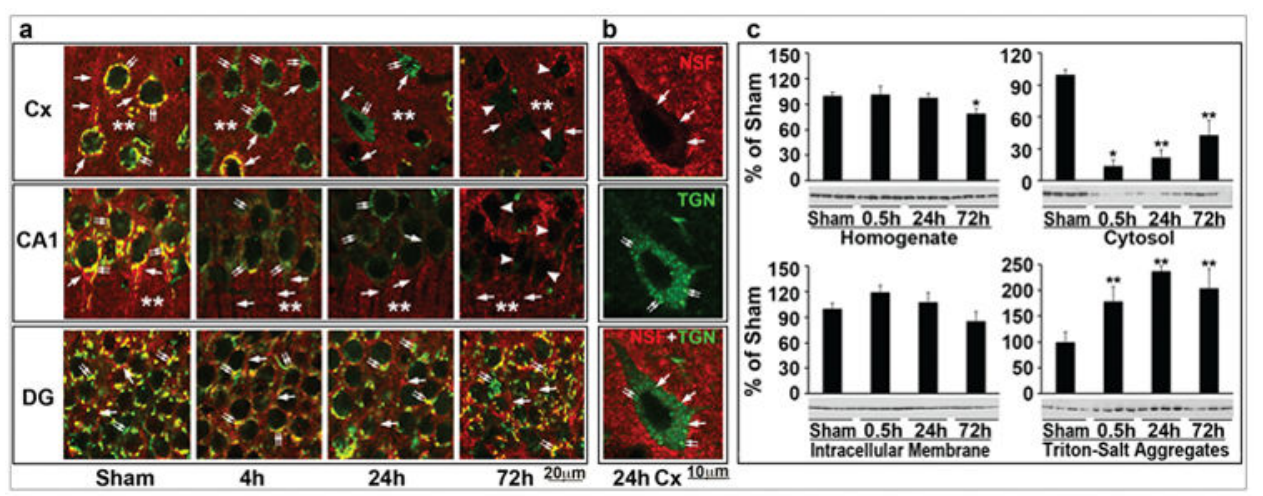

Fig. 4.

a Confocal microscopic images of $\mathrm{Cx}, \mathrm{CA} 1$, and DG neurons double-immunolabeled with NSF (red) and TGN38 (green) antibodies. Brain sections were obtained from sham-operated control rats and rats subjected to $20 \mathrm{~min}$ of cerebral ischemia followed $0.5,24$, and $72 \mathrm{~h}$ of reperfusion. Arrows indicate NSF immunostaining (red). Double arrows point to TGN38 immunostaining (green). Stars denote the neuropil region. b Higher magnification micrographs of a 24-h reperfused Cx neuron (24 h Cx) from a, NSF immunostaining (upper, red), TGN38 immu-nostaining (middle, green), merged immunostaining of NSF (red) and TGN38 (green) (lower, red + green). Arrows indicate depletion of NSF from the cytoplasm. Double arrows point to TGN38 immunostaining (green). Stars denote the neuropil region. c Western blot analysis of NSF protein in subcellular fractions. The Cx tissue samples were obtained from sham-operated rats or rats subjected to $20 \mathrm{~min}$ of cerebral ischemia followed by $0.5,24$, or $72 \mathrm{~h}$ of reperfusion. Densitometry of the gray value of the protein band was performed with the ImageJ software. Data are expressed as percentage of sham-operated control (mean \pm SEM, $n=4$ ). One-way ANOVA followed by Tukey post-hoc tests were used for statistical analysis. ${ }^{*} \mathrm{p}<0.05$ and $* * p<0.01$, sham vs. post-ischemic group 


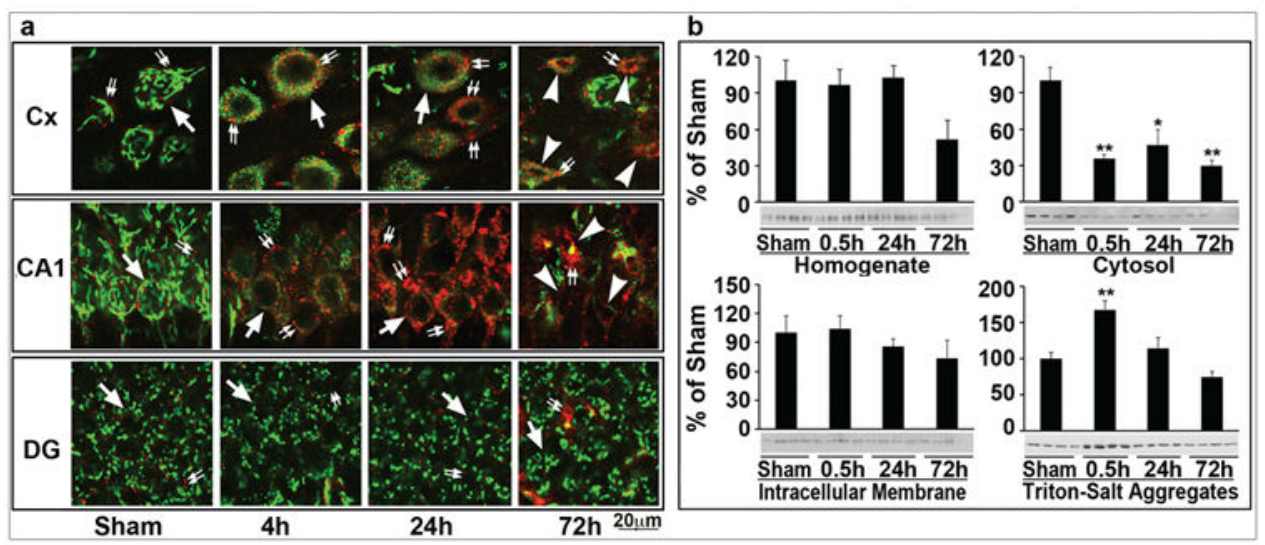

Fig. 5.

a The time course changes in TGN38 (green) and CTSB (red) immunostaining. The same set of brain sections as in Fig. 4 were used. Arrows indicate TGN38 immunostaining. Double arrows denote CTSB immunostaining. Arrowheads point to dead neurons. $\mathbf{b}$ We s $t \mathrm{e}$ $\mathrm{r} n \mathrm{~b} l$ o t $\mathrm{t}$ i $\mathrm{n} \mathrm{g}$ of TGN38. The same sets of Cx tissue samples and quantitative analysis method as in Fig. 4c were used. Data are expressed as percentage of sham-operated control (mean \pm SEM, $n=4$ ). One-way ANOVA followed by Tukey post-hoc tests. ${ }^{*} p<0.05$ and $* * p<0.01$, sham vs. post-ischemic group 

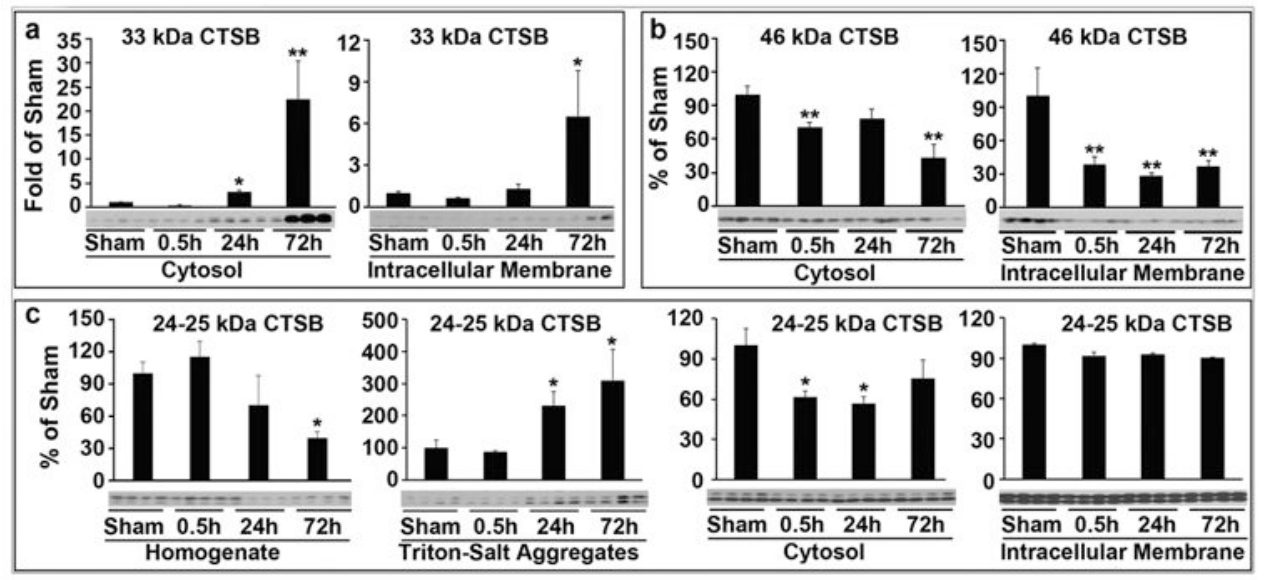

Fig. 6.

Western blot analysis of CTSB. The same sets of Cx tissue samples and quantitative analysis method as in Fig. 4C were used. a $33 \mathrm{kDa}$ CTSB, b $46 \mathrm{kDa}$ CTSB, and c 24-25 kDa CTSB. The CTSB antibody (CST Cat. \#31718, 1:1000 dilution) used in this study labeled mainly the CTSB bands and without noticeable non-specific bands. Data are expressed as fold (a) or percentage (b and $\mathbf{c}$ ) of sham-operated control (mean \pm SEM, $n=4$ ). One-way ANOVA followed by Tukey post-hoc tests were used for statistical analysis. ${ }^{*} p<0.05$ and $* * p<$ 0.01 , sham vs. post-ischemic group 


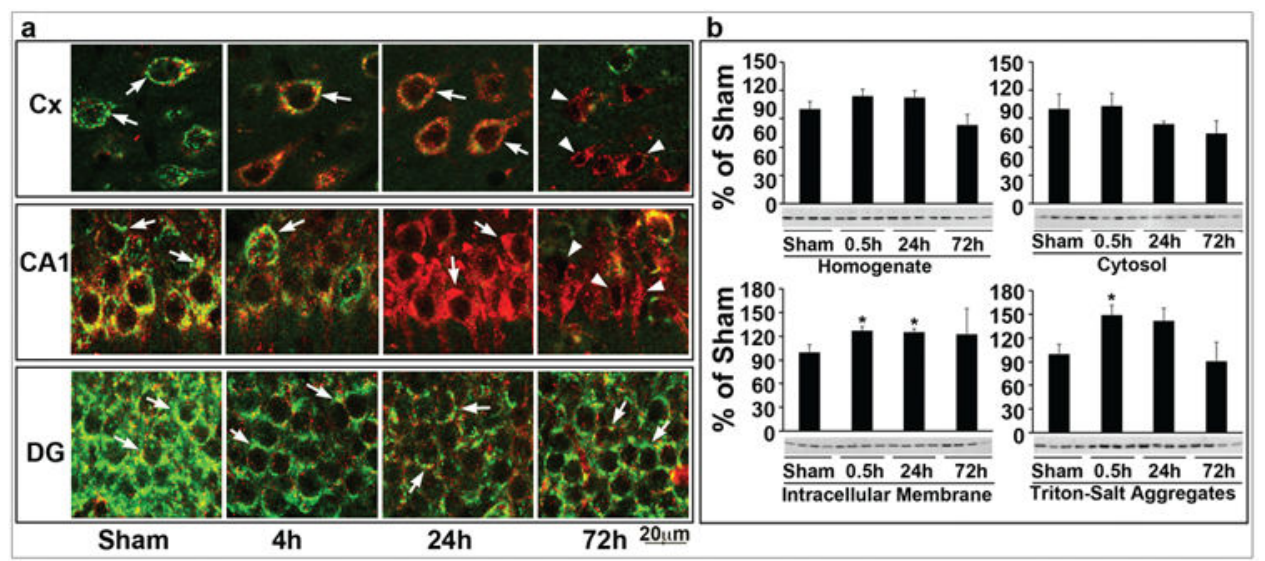

Fig. 7.

a Confocal microscopic images of hippocampal sections double-immuno labeled with CTSB (red) and Vti1b (green) antibodies. The same set of brain sections as in Fig. 4 were used. Arrows indicate living neurons. Arrowheads point to dead neurons. b Western blot analysis of Vti1b. The same sets of Cx tissue samples and quantitative analysis methods as in Fig. 4c were used. Data are expressed as percentage of sham-operated control (mean $\pm \mathrm{SEM}, n=4$ ). One-way ANOVA followed by Tukey post-hoc tests were used for statistical analysis. * $p<$ 0.05 , sham vs. post-ischemic group 